\title{
As imagens de vídeos amadores e de vigilância no telejornalismo: um estudo sobre as práticas jornalísticas contemporâneas
}

\author{
Leonel Azevedo de Aguiarl \\ Ana Paula Goulart de Andrade²
}

\section{Resumo}

A proposta deste artigo é apresentar os resultados de uma pesquisa sobre as práticas jornalísticas contemporâneas que utilizam imagens de vídeos de vigilância e de vídeos produzidos por amadores na construção das narrativas do telejornalismo. A partir das metodologias de inspiração etnográfica utilizadas pelos estudos de newsmaking, interpreta as entrevistas realizadas com jornalistas de televisão, no intuito de tentar compreender como são afetadas as práticas jornalísticas desses profissionais devido aos desafios tecnológicos que estão ressignificando o campo jornalístico. Visa também demonstrar, através de autores das Teorias do Jornalismo, de que forma os valores éticos da comunidade profissional dos jornalistas estão sendo afetados por novos contornos impostos pelas tecnologias digitais de informação e comunicação e seus rápidos avanços tecnológicos.

Palavras-chave: Teoria do Jornalismo. Telejornalismo. Práticas jornalísticas.

\section{Amateur and surveillance videos in TV news broadcast: A study on contemporary practices in journalism}

\footnotetext{
1 Professor do Departamento de Comunicação Social e professor do Programa de Pósgraduação em Comunicação da PUC-Rio. Doutor e Mestre (UFRJ). Jornalista diplomado (UFF). Líder do Grupo de Pesquisa Teorias do Jornalismo e Experiências Profissionais. E-mail: laaguiar@vol.com.br.

2 Doutoranda do Programa de Pós-graduação em Comunicação da PUC-Rio. Mestre em Comunicação (PUC-Rio). Jornalista diplomada (Unesa). Integrante do Grupo de Pesquisa Teorias do Jornalismo e Experiências Profissionais. Professora de jornalismo na graduação e pós-graduação (UFRJ, Facha e FPG). E-mail: goulartdeandrade@gmail.com.
}

Revista Pauta Geral-Estudos em Jornalismo, Ponta Grossa, v. 6, n. 2, p. 194-211, Dez/Jul, 2019. 


\section{Abstract}

This paper presents the results from a study on contemporary practices in Journalism about the use of surveillance and amateur videos to build TV news broadcast narratives. Inter-views with TV journalists were interpret based on ethnography-inspired methods employed in newsmaking researches, and aimed to understand how their journalism practices are affected by technological challenges, which have been providing new means for the Journal-ism field. Based on scholars from Journalism theories, this study intends to explain in which ways the journalism's ethics has been impacted by new shapes imposed by information and communication digital technologies, and their rapid transformation.

Keywords: Journalism theory. TV news broadcast. Practices in journalism.

\section{Introdução}

Esse artigo visa compreender o uso de imagens originadas em câmeras amadoras e de vigilância como prática relativamente nova e crescente na construção de narrativas telejornalísticas. Para além do que vem sendo tratado como "jornalismo colaborativo", efeito da popularização das mídias digitais e da cultura participativa da chamada web 2.0, esse trabalho identifica uma possível mudança nos critérios de noticiabilidade e na prática de elaboração de produtos noticiosos televisivos tomando como ponto de partida a inserção de conteúdos audiovisuais capturados pelo cidadão comum e pelos circuitos de vigilância nos textos do telejornalismo contemporâneo.

O trabalho está baseado em uma pesquisa sobre as rotinas produtivas no telejornalismo contemporâneo (GOULART DE ANDRADE, 2014), que identifica o uso dessas imagens uma narrativa formada - no todo ou em parte - pela apropriação de imagens audiovisuais que não foram produzidas segundo o rigor técnico próprio do jornalismo televisivo constituído; ao contrário, tais imagens não são fruto da produção jornalística, mas sim da atual possibilidade tecnológica que favorece o registro de quase tudo que se vivencia no cotidiano. Os cinegrafistas amadores e os circuitos de segurança são testemunhas dos acontecimentos, porém não são bem compreendidos nas sendas daquilo que se convenciona classificar de jornalismo em seu sentido tipicamente oriundo da Modernidade - até porque não gozam da credibilidade que foi historicamente atribuída a instituição empresarial jornalística. 


\section{REVISTA PAUTA GERAL}

\section{ESTUDOS EM JORNALISMO}

10.5212/RevistaPautaGeral.v.6.i2.00012

Para unificar os constructos teórico-metodológicos que norteiam as reflexões sobre o tema, são utilizados postulados já consolidados advindos das Teorias do Jornalismo, destacando a construção social da realidade, além dos regimes de visibilidade e vigilância na cibercultura e a cultura participativa.

No intuito de reconhecer as características que envolvem a produção, edição e veiculação do telejornalismo contemporâneo, bem como suas motivações e seus interstícios, são destacados os modos de operação do fazer telejornalístico para tentar compreender que impactos essa rotina traz aos profissionais que perfilam nos atuais quadros das redações jornalísticas. A pesquisa de inspiração etnográfica está baseada em depoimento de informantes - ou seja, os jornalistas - e tem, como objetivo, buscar interpretações sobre as práticas discursivas dos jornalistas e perceber como eles estruturam as notícias e constroem as narrativas telejornalísticas com inserções constantes de imagens que não são construídas pelo aparato organizacional da instituição jornalística. Dessa forma, esse artigo se inclina para a uma discussão sobre a deontologia do jornalismo, ao desvelar de que forma o uso dessas imagens estão interferindo e tensionando a comunidade jornalística.

\section{Jornalismo e construção social da realidade}

No telejornalismo contemporâneo, os discursos jornalísticos podem ser interpretados como dispositivos que evidenciam representações sociais da realidade. As notícias são, portanto, construções discursivas em que a noticiabilidade de um acontecimento vai depender justamente de um campo de força dos jogos de poder-saber. No campo jornalístico estão, de um lado, as empresas de comunicação; de outro, a comunidade interpretativa (TRAQUINA, 2008) dos jornalistas. O palco dessa relação de comunicação é um fluxo contínuo de critérios maleáveis e volúveis e que, assim, vão construindo uma infinidade de discursos. Não há, portanto, um processo fixo que estabeleça um esquema ordenado de noticiabilidade; existe, sim, um caráter de negociação nessa fatura da informação, exercida pelos profissionais que agregam diferentes níveis de importância aos acontecimentos. Ademais, é entender que existem percursos de interpretação ao longo do acontecimento que vão levando a notícia a ser construída e que não cessa. Durante a produção de um discurso, os jornalistas se concentram no que é desvio: a notícia é considerada a "contramão do óbvio", classificando os fatos noticiáveis naquilo que, prioritariamente, constitui uma infração, um 


\section{REVISTA PAUTA GERAL}

\section{ESTUDOS EM JORNALISMO}

10.5212/RevistaPautaGeral.v.6.i2.00012

desvio, uma ruptura, um desconcerto. Sendo assim, o acontecimento, que se constrói em notícia, é aquele que consegue alterar a rotina cotidiana.

Nessa perspectiva, o conteúdo utilizado na divulgação de um produto jornalístico deve estar baseado nos valores-notícia e obedecem a certos critérios. Os newsvalues (TUCHMAN, 1983) representam também esse lugar de contar histórias e vão preencher esse campo da questão central nesse jogo de forças do poder e saber do discurso no jornalismo como construção da realidade. Os valores-notícia se destacam não só pela posição das instituições de comunicação que veiculam as notícias e dos produtores que a constroem, mas, agora, pelo receptor que se tornou também um polo emissor público. 0 avanço tecnológico permitiu que os meios de comunicação criassem novas formas de ação e interação. Com o desenvolvimento dos sistemas de tecnologias digitais e, consequentemente, os novos tipos de relacionamentos sociais no jornalismo, emergiram as audiências ativas, que não podem ser descartadas. Surge, portanto, uma complexa reorganização de padrões, um novo arranjo social.

É através da teoria do newsmaking que podemos considerar os discursos jornalísticos como dispositivos que interagem nos processos de construção social da realidade. Segundo Traquina (2012), as notícias são construções discursivas, constituídas por narrativas que reúnem condições e possibilitam a ocorrência compartilhada socialmente da realidade. Trata-se de um conjunto de exigências não só de quem estrutura as notícias - considerando atualmente a cultura participativa -, mas também da ambiência das instituições que as produzem e veiculam. É dessa maneira que o acontecimento adquire forma pública e é efetivado como discurso jornalístico, sendo elevado ao grau de notícia. Desse modo, compreender a realidade como socialmente construída significa que existir na vida cotidiana é estar continuamente em interação e comunicação com os outros, sejam indivíduos, instituições, culturas ou forças sociais (BERGER; LUCKMANN, 2003).

Miquel Alsina (2009) afirma que não se deve vincular o conceito de "construção social da realidade" única e exclusivamente à prática jornalística. Para ele, essa formação está na própria vida cotidiana e se consolida através de um processo de institucionalização das práticas e dos papéis de quem as constroem. É algo, paralelamente, social e intersubjetivamente construído. 


\section{REVISTA PAUTA GERAL}

\section{ESTUDOS EM JORNALISMO}

10.5212/RevistaPautaGeral.v.6.i2.00012

Isso faz caracterizarmos a atividade jornalística como um papel socialmente legitimado para gerar construções da realidade publicamente relevantes. Portanto, podemos dizer que os jornalistas têm um papel social legitimado e institucionalizado para construir a realidade social como realidade pública e socialmente relevante. Essas competências são realizadas no interior de aparatos de produção específicos: a mídia (ALSINA, 2009, p.46).

Pela teoria do newsmaking, observa-se o desempenho do gatekeeper, que funciona como uma "cancela", por onde um fluxo de notícias precisa ir além e conseguir passar pelos "gates". Essa função é exercida por profissionais que ocupam algum tipo de chefia e detêm um poder maior na aplicação aos critérios de noticiabilidade previstos nas empresas de comunicação. O gatekeeper é quem organiza a estrutura das notícias no veículo em que trabalha, classificando-as em níveis de importância, descartando as menos interessantes.

No caso da seleção de imagens de câmeras de vigilância e amadoras na construção de narrativas televisivas, está incluída na função do gatekeeper garimpar, selecionar e organizar conteúdos da internet, sobretudo de redes sociais, e transpor para a televisão. Ora, se as visualizações da plataforma internet foram significativas, isso pode ser indicador de audiência na televisão, proporcionando um agendamento intermídia. Segundo McCombs (2009), o agendamento intermídia fundamenta-se pela construção de uma agenda da mídia com base não só na agenda pública, mas tomando por referência outros veículos, dentre os quais blogs e web sites. O que chama a atenção nessas imagens que trafegam entre internet e televisão na contemporaneidade é que esses meios se retroalimentam a partir dessa circulação de produtos audiovisuais. Como os sites de redes sociais, com milhares de usuários cadastrados, disponibilizam conteúdos com uma velocidade de atualização relativamente maior que as redações de telejornais, eles se constituem como ferramenta eficaz para a garantia de audiência.

Dessa forma, para além do gatekeeper, podemos afirmar que o jornalista assume a função de gatewatcher (BRUNS, 2005). O conceito surgiu com a revolução tecnológica trazida pela internet que alterou as formas de produção jornalística se integrando ao processo de como estão sendo construídas as notícias influenciando, portanto, no processo de agendamento de um acontecimento. Do mesmo modo, mais do que portões que têm o poder de determinar qual acontecimento será veiculado, de acordo com o valornotícia que julgar mais atraente e adequado, conforme a linha editorial do veículo, o 


\section{REVISTA PAUTA GERAL}

\section{ESTUDOS EM JORNALISMO}

10.5212/RevistaPautaGeral.v.6.i2.00012

gatewatcher funciona como uma sentinela, um espião, alguém que observa e vigia quais acontecimentos poderiam ser reformatados e redistribuídos. Assim, ao voltar-se para a web na captação de acontecimentos, o telejornalismo contemporâneo tenta renovar os seus critérios de produção para manter-se cada vez mais atraente e espetacular, muitas vezes com histórias e imagens sensacionais e que, na maioria das vezes, já foram consumidas na rede. O que se observa é a apropriação de um material produzido para uma plataforma, bem como o uso de elementos interativos fundamentados na web. De fato, alguns desses produtos podem até trazer um indício para uma determinada matéria, reportagem e até mesmo abastecer o jornalismo informativo e investigativo. No entanto, muitas das vezes, o que se vê é a reprodução de uma falácia audiovisual que espetaculariza a imagem, na medida em que atribui ao conteúdo visual informações que exploram a cena por si só agregando um discurso quase dramatúrgico, tendo como álibi o jornalismo colaborativo.

Os jornalistas, movidos pelo embalo tecnológico e obedecendo a um regime de tempo cada vez mais escasso - principalmente pela sinergia dos meios de comunicação imputando uma concorrência cada vez mais difusa, conforme as normas que a instituição impõe -, estão sujeitos a um nível potencializado dos constrangimentos organizacionais próprios da atividade jornalística. Se o trabalho jornalístico depende de recursos utilizados na organização, somado ao fato que o jornalismo é um negócio estruturado enquanto empresa, o fator financeiro é inevitável e também interfere na construção da produção da notícia.

\footnotetext{
$\mathrm{Na}$ televisão, a publicidade impõe, sobretudo, a lógica das audiências, seguindo a lógica de 'mais audiências, mais receitas publicitárias'. Assim sendo, o conteúdo noticioso do jornal televisivo pode ser influenciado pela dimensão econômica: são incluídos no noticiário os acontecimentos noticiosos que julgam ser do maior interesse para o maior número de público (TRAQUINA, 2005, p. 158).
}

Como resultado, é possível ver que, cada vez mais, os telejornais incluem conteúdos advindos de imagens de vídeos de vigilância e amadoras nos telejornais, colocando em xeque a qualidade do jornalismo. Antes de compreender o comportamento dos profissionais de televisão e esse modo de fazer telejornalismo contemporâneo admitindo a construção de produtos telejornalísticos sensacionais que alimentam a programação com um custo bem menor face às mudanças tecnológicas -, pretende-se 


\section{REVISTA PAUTA GERAL}

\section{ESTUDOS EM JORNALISMO}

10.5212/RevistaPautaGeral.v.6.i2.00012

buscar pistas para tentar entender por que especialmente o telejornalismo é uma das instâncias da produção de massa que mais tem ressentido essas transformações por novos dispositivos óticos popularizados e a interferência disso nas rotinas produtivas do telejornalismo.

\section{Tecnologias e espetacularização das imagens}

A busca incessante das emissoras por imagens sensacionais, afeta diretamente 0 comportamento do cidadão comum. Algumas vezes como produtor ou colaborador de um acontecimento, outras como o próprio acontecimento. Dessa maneira, é válido considerar a sinalização de Bauman sobre a questão do público versus privado, em que tudo o que é privado "agora é feito potencialmente em público - e está potencialmente disponível para consumo público; e sempre continua disponível, até o fim dos tempos" (BAUMAN, 2013, p.28). Para ele, a internet não pode se esquecer de nenhum dos incontáveis registros de seus servidores.

\footnotetext{
Essa erosão do anonimato é produto dos difundidos serviços da mídia social, de câmeras em celulares baratos, sites grátis de armazenamento de fotos e vídeos e, talvez o mais importante, de uma mudança na visão das pessoas sobre o que deve ser público e o que deve ser privado (BAUMAN, 2013, p.29).
}

Igualmente como nas imagens amadoras, ao falar de circuitos de vigilância é fundamental considerar o público que ora corrobora com o fato, ora é o fato em si. Talvez o conceito de panóptico (FOUCAULT, 2011) já não mais consiga dar contadas questões que hoje o circuito de vigilância provoca. A docilidade dos corpos cedeu lugar à ação das vozes que se reverberam potencialmente na produção e circulação de produtos pretensamente noticiosos. Desse modo, o sinóptico (BAUMAN, 1999) não determina o lugar a ser vigiado, mas atribui não só sedução, mas também deslumbre aos indivíduos que são convocados a participar das cenas públicas como produtores e muitas vezes como personagens de uma notícia, na qual são facilmente enquadrados nos acontecimentos que viram produto televisivo, construídos a partir de imagens desses circuitos fechados. Na medida em que os telejornais propagam esse tipo de veiculação, pelo poder característico de penetração da TV, esses discursos ganham visibilidade potencializada e, com isso, legitimação. O "ver e ser visto" se constitui como um importante elemento na contemporaneidade. Mais ainda: esse conteúdo alimenta e é 


\section{REVISTA PAUTA GERAL}

\section{ESTUDOS EM JORNALISMO}

10.5212/RevistaPautaGeral.v.6.i2.00012

alimentado pela internet, onde as pessoas parecem agir naturalmente "na cena" ao ser capturado por uma imagem de videovigilância. Nessa perspectiva, esse recurso ajuda a construir uma realidade que se estabelece com diferentes atores (LATOUR, 1994). Desse modo, acrescente proliferação da videovigilância aponta para uma "naturalização do ato de vigiar como modo de olhar e prestar atenção na contemporaneidade" (BRUNO, 2008).

Explicar que a farta produção e disseminação de conteúdo audiovisual que recobre a cena cotidiana através de vídeos compartilhados em diversas plataformas de mídias se deve à popularização de dispositivos digitais implica, claramente, em um determinismo tecnológico infrutífero. Parece ser claro que as empresas de comunicação e as instâncias de produção do jornalismo, mais do que acolher, incitam a produção de imagens amadoras dando escoamento a uma multiplicidade da exposição da vida privada (SIBILIA, 2008; BRUNO, 2005) materializada no "fazer imagem" da produção amadora. Dessa forma, o olhar do cidadão comum, acostumado por décadas de exposição ao enquadramento da cultura de massa (com atenção especial à estética televisiva), é plenamente aceitável em termos de operação simbólica. É justamente isso que cria a possibilidade de apropriação pela mídia audiovisual da exibição da vida comum de seus telespectadores, algo que a consagração do formato "reality show" corrobora.

Se a legitimação de si dada pelo olhar do outro (BRUNO, 2005) é fundamental para explicar o impulso da cessão de imagens amadoras aos canais midiáticos tradicionais, por outro lado, a máquina jornalística tem que "dar voz" ao público para garantir a já consensual lógica participativa própria da cibercultura. Neste sentido, amador e profissional são dois conceitos que funcionam como lados opostos da mesma moeda, ou seja, ao contrário do que foi outrora, hoje estão circunscritos ao mesmo universo de produção e reprodução de conteúdos para que, assim, se possa garantir um contrato tácito que se firma na ecologia das trocas simbólicas da contemporaneidade.

É necessário destacar alguns aspectos que perpassam esse arranjo. Em primeiro lugar, toda vez que um telejornal se utiliza de imagens amadoras, ao fazê-lo, sublinha que o que se exibe constitui-se de imagens cedidas. Muito mais que terceirizar os créditos de autoria (o que aparentemente surge como um cuidado ético), a instância jornalística se exime automaticamente de qualquer responsabilidade sobre os conteúdos exibidos, exportando o "ônus da prova" ao eventual cinegrafista amador que efetivamente capturou o vídeo e concedeu-o ao telejornal. É possível ver nessa prática uma mudança nos critérios de noticiabilidade e um efeito de sentido que mantém uma perspectiva de 


\section{REVISTA PAUTA GERAL}

\section{ESTUDOS EM JORNALISMO}

10.5212/RevistaPautaGeral.v.6.i2.00012

imparcialidade por parte do telejornal, que não teria empregado esforços para produção das imagens que exibe.

Em segundo lugar, no jogo que une o profissional e o amador, se instaura uma confusão de fronteiras que faz parecer que o canal e o público intimam um "fazer conjunto", que, entretanto, é meramente retórico. Mesmo que a matéria telejornalística seja composta por elementos que combinam a produção midiática e a participativa, o eventual cinegrafista amador não finaliza o produto jornalístico, tendo sido um mero colaborador pragmático, sem, contudo, realmente cooperar - numa alusão a uma "criação coletiva" e a uma interação mútua, conforme Primo (2007, p. 99-134). Dito de outra maneira, em contraposição ao que a narrativa faz parecer, o enquadramento dos fatos recobertos por imagens de câmeras amadoras não implica a coordenação da visão do telejornal com a do cedente das mesmas imagens. O que ocorre é que o acabamento (e tudo que esse acabamento implica) se restringe ao direcionamento dado pela instância jornalística, independente de coincidir ou não com a intenção, crença ou desejo daquele que "ofertou" parte significativa do que vai compor o produto jornalístico final que será exibido.

Apesar disso, nota-se na atualidade um grande alarde feito pela mídia constituída em torno do efusivo reconhecimento do consumidor/produtor como célula fundamental para a consolidação de uma cultura participativa que orquestra as bases de um jornalismo renovado. Entretanto, percebemos que há mais uma performance, sem ser de fato um "dar voz ao cidadão". O próximo passo, então, é mostrar que o telejornalismo com uso das imagens amadoras e de vigilância ultrapassa as implicações do que se tem chamado de cultura participativa.

\section{Além da produção colaborativa}

O telejornalismo, enquanto lugar de referência (VIZEU, 2007), é um ambiente que tem sido fortemente marcado pela superabundância de exposição de acontecimentos expressos em imagens oriundas de circuitos fechados de televisão e câmeras amadoras, que têm transitado facilmente no espaço midiático, não só pela contribuição dada do que tem se do jornalismo participativo, mas sob o aspecto da estrutura e construção do processo que transforma um acontecimento em notícia.

Ocorre que, para mais além desse fenômeno, que se percebe hoje é que os produtos audiovisuais, captados pelo cidadão comum, não apenas ajudam a contar uma 


\section{REVISTA PAUTA GERAL}

\section{ESTUDOS EM JORNALISMO}

10.5212/RevistaPautaGeral.v.6.i2.00012

história, mas podem estar encharcado de outras intenções e os jornalistas televisivos, regidos pela tirania do tempo, "aproveitam" e apropriam-se desse conteúdo para dar conta de cumprir suas rotinas diárias de produção, colocando em segundo plano a importância da qualidade do jornalismo informativo e, também, dos seus critérios e crenças profissionais. Os "cidadãos e cidadãs comuns" já perceberam o poder que possuem enquanto agentes participativos e tecnologicamente pertencidos às notícias televisivas. É claro que é característico da democracia algo se tornar público para ser questionado, mas é preciso ter em mente qual é a intencionalidade dessas imagens que, em princípio, parecem inofensivas. Assim, utilizar confiantemente os conteúdos cedidos e/ou negociados por cidadãos comuns, recorrentemente como fonte, representa um risco.

Apesar de guardar características semelhantes e servir de inspiração, a ideia de jornalismo colaborativo não se mostrou suficiente para pontuar as inquietações que ora tensionam a relação da construção da notícia com imagens produzidas em contextos de videovigilância e de cinegrafia amadora. Parece que enquanto o jornalismo colaborativo se preocupa com o que vem de fora para dentro nessa relação entre público e empresa jornalística; o telejornalismo apócrifo se concentra no polo emissor dos discursos oriundos de dentro para fora desse processo comunicacional, ou seja, no resultado exibido e mais ainda, legitimado pelos telejornais e pouco contestado, dado o fluxo contínuo de produtos distribuídos e que circulam diariamente nas telas de TV.

Por esse caminho, e com o intuito de redimensionar essas questões no estudo do telejornalismo, empreende-se aqui a tarefa de dar conta de aprofundamentos teóricometodológicos que se corporificam na proposição do conceito de "telejornalismo apócrifo". Esse modelo de telejornalismo considera a construção de modos contemporâneos de interpretação dos fatos cotidianos a partir de perspectivas construídas por dispositivos audiovisuais operados por "leigos", ou seja, que se origina (ou flerta) no exterior dos modos modernos do fazer jornalístico.

Vale a menção de que, portanto, a expressão "telejornalismo apócrifo" não pretende questionar o lugar de autoria, mas sim a autenticidade que é atribuída ou não ao telejornalismo que se utiliza de imagens amadoras ou de vídeo-vigilância na constituição de seus produtos noticiosos. O conceito de telejornalismo apócrifo coloca em evidência o lugar de fala e as relações de poder-saber na composição de narrativas jornalísticas, justamente porque envolve a visibilidade e a legitimação no processo que transforma o acontecimento produzido em condições polifônicas. 


\section{REVISTA PAUTA GERAL}

\section{ESTUDOS EM JORNALISMO}

10.5212/RevistaPautaGeral.v.6.i2.00012

O que é indiscutível é que o telejornalismo apócrifo tem se tornado uma prática contumaz na composição dos noticiários televisivos. Talvez a dinâmica das imagens apócrifas seja mais sedutora do que a transmissão de informações que, mesmo muito relevantes, se restrinjam a cenas "estáticas" de apresentadores narrando "notas secas"3. Além de ilustrar a notícia, a sequência de imagens invariavelmente explora o movimento visual requerido pelo telespectador ávido por estímulos sensoriais mais intensos. Pesquisa comparativa que realizamos (GOULART DE ANDRADE, 2014) entre três telejornais nacionais de emissoras diferentes ("Jornal Nacional”, "Jornal da Record" e "SBT Brasil") demonstrou essa avalanche de conteúdos ilustrados por imagens de videovigilância e amadoras na construção do telejornal e apontou que chega a 40 \% a porcentagem de preenchimento nos noticiários com esses conteúdos. Foram verificados continuamente 328 produtos telejornalísticos ${ }^{4}$ - transmitidos no período de 27 a 31 de maio de 2013.

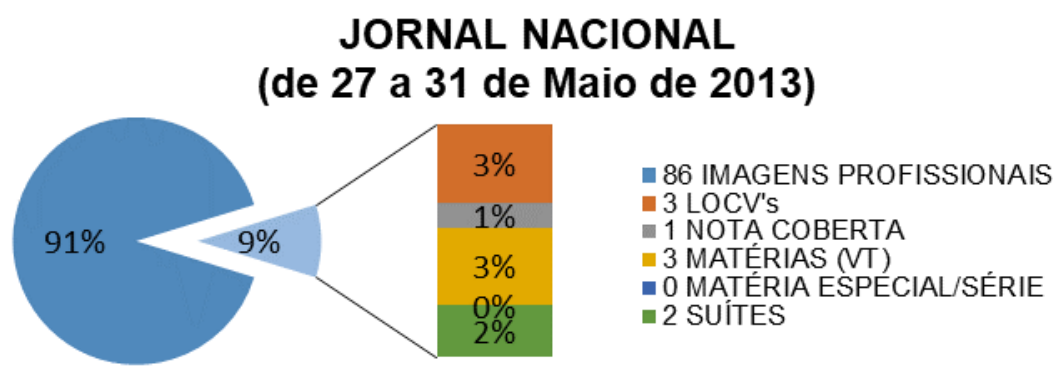

Gráfico 1: Jornal Nacional (dos autores)

\footnotetext{
3 Segundo Paternostro (1999), nota seca (ou nota pelada) refere-se a informação lida pelo apresentador sem cobertura de imagem. Atualmente, as notas secas - aposta-se que, muito em parte, justamente pela alta frequência do jornalismo apócrifo - tem praticamente se relegado a apresentação de notícias relevantes de última hora.

${ }_{4}^{4}$ Consideramos aqui como produtos telejornalísticos aqueles que são exibidos com off (texto jornalístico de televisão) e imagem.
}

Revista Pauta Geral-Estudos em Jornalismo, Ponta Grossa, v. 6, n. 2, p. 194-21 1 , Dez/Jul, 2019. 


\section{REVISTA PAUTA GERAL}

\section{ESTUDOS EM JORNALISMO}

10.5212/RevistaPautaGeral.v.6.i2.00012

JORNAL DA RECORD

(de 27 a 31 de Maio de 2013)

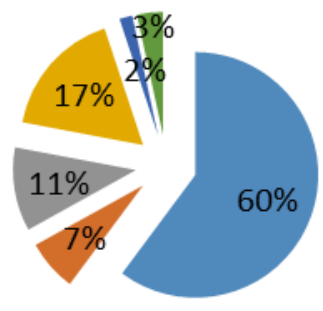

- 71 IMAGENS PROFISSIONAIS

$\because 8$ LOCV's

13 NOTAS COBERTAS

20 MATÉRIAS (VT'S)

- 2 MATÉRIAS ESPECIAIS

4 SUITES

Gráfico 2: Jornal da Record (dos autores)

\section{SBT BRASIL}

(de 27 a 31 de Maio de 2013)
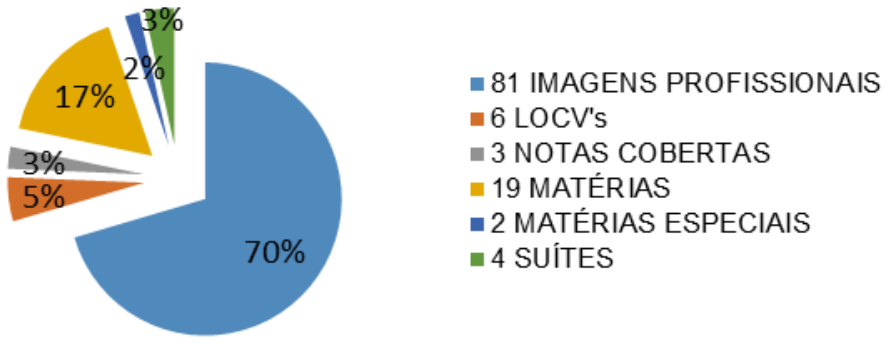

Gráfico 3: SBT Brasil (dos autores)

Diante dos gráficos, é possível perceber o quanto que as imagens amadoras e de vigilância já fazem parte do escopo da realidade construída pelo imaginário do público espectador que já manuseia com naturalidade e intencionalidades os dispositivos amadores, tanto quanto já se apropria das mais diversas imagens depositadas em sites de compartilhamento de vídeos da internet. Essa prerrogativa é o que viabiliza as imagens apócrifas serem acionadas pelos telejornais como objetos naturais de composição de narrativas a serem veiculadas.

É importante esclarecer que a proposta do artigo não é condenar ou absolver o uso de imagens amadoras ou de vigilância na constituição telejornalística. O foco é buscar de que forma essas cenas estão sendo inseridas na narrativa telejornalística e quais os critérios que obedecem ao serem legitimadas pelo jornalismo televisivo. O conceito de telejornalismo apócrifo transforma-se em mais um elemento de inspiração para se 


\title{
REVISTA PAUTA GERAL
}

\section{ESTUDOS EM JORNALISMO}

10.5212/RevistaPautaGeral.v.6.i2.00012

investigar os desafios impostos à atividade jornalística no mundo contemporâneo, dada a circulação excessiva e flutuante de informações num cenário digital que obriga o jornalista a repensar o seu papel e a sua forma de atuação no processo produtivo, sobretudo nos telejornais. Contribuir nessa direção é o que se intenta, buscando relatos com profissionais que constituem discursos jornalísticos televisivos e estão diante desse cenário.

\section{A tribo jornalística}

A descrença e falta de perspectivas nas mudanças públicas sobre o jornalismo podem estar, de fato, afetando os modos de produção e o comportamento dos profissionais. O incentivo das empresas para a publicização de produtos apócrifos, a qualquer preço, parece rondar as emissoras de TV em uma busca incessante por resultados imediatistas, subjugando as rotinas dos jornalistas que, cada vez mais, são obrigados a conviver com os constrangimentos organizacionais, conforme apontou Traquina (2008).

A apuração e checagem dos fatos talvez seja o ponto fundamental sobre a questão do telejornalismo apócrifo. Qual seria, portanto, o papel da mídia televisiva enquanto mediadora desses dois polos, do que é cedido e do que exposto?

\begin{abstract}
Essa relação entre o jornalista e seus destinatários estabelece-se por um contrato pragmático fiduciário social e historicamente definido. Os jornalistas têm a incumbência de recopilar os acontecimentos e os temas importantes e dar-lhes sentido. Esse contrato baseia-se em atitudes epistêmicas coletivas, que foram se compondo através da implantação do uso social da mídia como transmissores da realidade social e importância pública. A própria mídia é a primeira que realiza uma prática contínua de autolegitimação para reforçar esse papel social (ALSINA, 2009, p.47).
\end{abstract}

O ponto de partida para compreender como que os jornalistas estão se comportando diante desse cenário, está baseado em entrevistas de caráter etnográfico em redações. Parte desse resultado serviu como método de averiguação do corpus desse trabalho. As perguntas giraram em torno de vários aspectos. No entanto, três foram eleitos para ilustrar esse artigo. São eles: a) a checagem e apuração dos conteúdos imagéticos antes da exibição; b) a retroalimentação entre TV e internet com esses produtos telejornalísticos; c) a perspectiva do telejornalismo a partir dessa lógica de produção. 


\section{REVISTA PAUTA GERAL}

\section{ESTUDOS EM JORNALISMO}

10.5212/RevistaPautaGeral.v.6.i2.00012

Ora, se conforme visto na análise comparativa, essas imagens são usadas para preencher tempo de programação e requisitadas pela produção jornalística a todo instante, parece comum que atendam aos critérios de noticiabilidade do jornalismo informativo. No entanto, o que ocorre diariamente pela tirania do tempo de fechamento dos telejornais, é uma escassez de dados e o risco de se propagar uma narrativa jornalística não confiável. A falta de apuração potencializa o perigo de publicar uma falsa notícia, conforme os recortes que realizamos das entrevistas feitas com três jornalistas.

Em relação à checagem, é lógico que a gente também tem que, às vezes, a gente não tem uma garantia, a gente não tem um atestado de idoneidade da pessoa que fez aquele vídeo ${ }^{5}$.

E quando a pessoa não oferece, não fornece informação nenhuma, mas a imagem é muito boa, pode trazer a audiência para a televisão, pode chamar e aguçar a curiosidade do telespectador, a gente divulga mesmo assim e geralmente o apresentador narra aquilo, quando a gente não tem informação nenhuma, entendeu? ${ }^{6}$.

Eu, às vezes, me surpreendo quando eu percebo que as perguntas básicas para a construção de uma notícia não são respondidas. Especialmente quando se trata de imagem de amador ${ }^{7}$.

Em outras palavras, o que está apontado é uma tentativa de escapar dessa malha fina, desse jogo onde o poder, saber se instaura no espaço midiático contemporâneo, considerando o telejornalismo como um local atravessado por mecanismos de poder, em que diariamente os profissionais, durante a produção das suas atividades jornalísticas, são colocados à prova ou exame. Dessa forma, criam artifícios para tentar escapar dos constrangimentos diários, segundo os jornalistas entrevistados para a pesquisa.

Eu preciso ver essas imagens e a partir daí construir uma notícia. Muitas vezes, ela não existe, mas, por conta de uma única imagem, a gente vai criar, entre aspas, uma informação para poder aproveitar aquele material ${ }^{8}$.

\footnotetext{
5 Jornalista (então editor) do Sistema Brasileiro de Televisão. Entrevista concedida aos autores. Rio de Janeiro, 12 jan. 2014.

6 Jornalista (então produtor) da Rede Record de Televisão. Entrevista concedida aos autores. Rio de Janeiro, 04 nov. 2013.

7 Jornalista (então editora) do Sistema Brasileiro de Televisão. Entrevista concedida aos autores. Rio de Janeiro, 9 jan. 2014.

8 Idem, ibidem.
}

Revista Pauta Geral-Estudos em Jornalismo, Ponta Grossa, v. 6, n. 2, p. 194-211, Dez/Jul, 2019 


\section{REVISTA PAUTA GERAL}

\section{ESTUDOS EM JORNALISMO}

10.5212/RevistaPautaGeral.v.6.i2.00012

Quem fez foi ele, a gente só está divulgando. A responsabilidade é da pessoa, não é nossa. A gente só está aqui para divulgar, porque a gente também quer que isso se resolva, sabe? ${ }^{9}$.

Vale lembrar que existe um acordo tácito entre os que escolhem esta profissão de jornalista e os telespectadores, no caso da mídia televisiva, que possibilita dar credibilidade ao jornalismo. Sendo assim, "o principal produto do jornalismo contemporâneo, a notícia, não é ficção, isto é, os acontecimentos ou personagens das notícias não são invenção dos jornalistas" (TRAQUINA, 2012, p.20). A função jornalística se fundamenta, em princípio, na seleção dos acontecimentos que são considerados jornalisticamente importantes.

O próximo passo foi conferir qual o papel que a internet desempenha na busca de matéria prima de conteúdos a serem exibidos. Conforme já pontuado nesse artigo, a web tem sido uma grande fonte de pautas televisivas, sobretudo as redes sociais. $O$ agendamento intermídia (McCOMBS, 2009) já é uma realidade e os jornalistas também começaram a perceber as consequências desse garimpo como forma de alavancar a audiência, conforme expressam nas entrevistas que foram concedidas para a pesquisa.

Às vezes o cara publicou uma imagem num blog. O blog tem, sei lá, por mais que o blog seja de sucesso. Vamos supor: um blog aí com cinquenta mil de visualizações dias, é um blog de sucesso. Mas quando vai para uma emissora de televisão, mesmo que de porte médio, a visualização já passa aí para a casa do milhão de telespectadores ${ }^{10}$.

O vídeo que a pessoa faz é uma ferramenta de proteção ou de acusação a alguém ou de afirmação de que aquela pessoa está ali. Se ela coloca na internet, vira uma coisa pública e uma coisa democrática ${ }^{11}$.

O que me preocupa é o resultado de curtíssimo prazo da audiência - e quando eu falo audiência, eu estou falando medição, de audiência como medição e não como conjunto de colaboradores -, o resultado da audiência de curto prazo provocado pelo uso dessas imagens ${ }^{12}$.

Por fim, analisando a dinâmica do telejornalismo contemporâneo, os jornalistas apontaram uma tendência para a terceirização dos serviços audiovisuais. Eles acreditam

9 Jornalista (então editora) da Rede Globo de Televisão. Entrevista concedida aos autores. Rio de Janeiro, 14 jan. 2014.

10 Ver nota 5.

11 Ver nota 9.

12 Jornalista 1 (então repórter) da Rede Record de Televisão. Entrevista concedida aos autores. Rio de Janeiro, 06 dez. 2013.

Revista Pauta Geral-Estudos em Jornalismo, Ponta Grossa, v. 6, n. 2, p. 194-211, Dez/Jul, 2019. 


\title{
REVISTA PAUTA GERAL
}

\section{ESTUDOS EM JORNALISMO}

10.5212/RevistaPautaGeral.v.6.i2.00012

numa perspectiva da diminuição das equipes tradicionais de televisão, realidade já comprovada no exterior.

\begin{abstract}
Acho que o jornalismo, o jornalismo de grandes empresas, de grandes redações, eu acho que ele vai reduzir, de fato. Acho que o que vai pipocar é o jornalismo digital, eletrônico que você com duas, três pessoas, você monta um blog, você ganha dinheiro com aquele blog, fazendo jornalismo e fazendo um Jornalismo bem feito ${ }^{13}$.

Eu lamento muito, mas a gente está caminhando para isso... uma redução nas equipes ${ }^{14}$.

Então eu acho que com certeza vai haver um enxugamento aí nas redações tanto de TV quanto de rádios. Eu acho que vai perder muito para os veículos de internet ${ }^{15}$.

Quanto mais imagens, quanto mais registros chegarem às tevês, mais apuradores teremos que ter, mais produtores teremos que ter, mais editores teremos que ter. Salvo, se exibirmos no ar apenas uma coletânea de registros e não uma coletânea de reportagens. Isso é uma questão de opção editorial ${ }^{16}$.
\end{abstract}

Pelos relatos, fica evidente que os jornalistas ainda não sabem lidar com esse tipo de imagem. A maioria apontou como perspectiva uma redução nas equipes telejornalísticas, indicando uma revisão urgente nas formas de se fazer o telejornalismo, já que o uso abundante de imagens amadoras e de vigilância pode colocar em risco a produção telejornalística de qualidade voltada para o interesse público.

\section{Considerações finais}

O uso indiscriminado de imagens apócrifas traz para a comunidade profissional dos jornalistas uma sensação de fragilidade diante da imperativa imposição tecnológica, de modo que os próprios jornalistas reconhecem que o principal artifício no combate à falta de qualidade do telejornalismo informativo é a exigência de novos moldes de conhecimento mais potentes, para lidar não apenas com o aparato tecnológico, mas para ser capaz de reconfigurar a construção das notícias diante da falácia produzida por tantos

\footnotetext{
13 Ver nota 5.

14 Jornalista 2 (então repórter) da Rede Record de Televisão. Entrevista concedida aos autores. Rio de Janeiro, 08 jan. 2014.

15 Ver nota 6.

16 Ver nota 12.
}

Revista Pauta Geral-Estudos em Jornalismo, Ponta Grossa, v. 6, n. 2, p. 194-21 1 , Dez/Jul, 2019. 


\section{REVISTA PAUTA GERAL}

\section{ESTUDOS EM JORNALISMO}

10.5212/RevistaPautaGeral.v.6.i2.00012

meios na era digital. Dessa forma é necessário elevar o nível dos produtos exibidos nos telejornalismos.

Para isso, o esforço não deve estar apenas em buscar o acontecimento e transformá-lo em notícia, pois a questão é a filtragem e a contextualização através de uma apuração mais cuidadosa, a fim de cumprir os requisitos necessários para dar conta da tarefa telejornalística, compreendendo os artifícios tecnológicos como apenas mais um elemento constituinte de um produto noticioso, passível por tanto de apuração e checagem de dados. Assim sendo, a nossa aposta é que para ocupar esse lugar de construtor da notícia televisiva contemporânea, deve ser necessário cumprir uma série de exigências, sobretudo capacitação política, social e cultural.

Assim, não se trata de encerrar essa pesquisa rotulando esse modelo de telejornalismo como positivo ou negativo. Percebe-se que é uma tendência e que a pesquisa em questão, longe de findar a discussão sobre o tema, compreende que o seu objeto ainda se encontra em processo de acomodação.

\section{Referências}

ALSINA, M.R. A construção da notícia. Petrópolis: Vozes, 2009.

BAUMAN, Z. Vigilância líquida. Rio de Janeiro: Jorge Zahar, 2013.

BAUMAN, Z. Globalização. Rio de Janeiro: Jorge Zahar, 1999.

BERGER, P.; LUCKMANN, T. A construção social da realidade. Petrópolis: Vozes, 2003.

BRUNO, F. Quem está olhando? Variações do público e do privado em weblogs, fotologs e reality shows. Contemporânea, Salvador, v. 3, no 2, p. 53-70, 2005.

BRUNO, F. Controle, flagrante e prazer: regimes escópicos e atencionais da vigilância nas cidades. Revista da Famecos, Porto Alegre, v. 1, no 37, p. 45-53, 2008.

BRUNS, A. Gatewatching: collaborative online news production. New York: Peter Lang Publishing, 2005.

FOUCAULT, M. Vigiar e punir. Rio de janeiro: Vozes, 2011.

GOULART DE ANDRADE, A. P. Telejornalismo apócrifo: perspectivas sobre o uso de imagens amadoras e de videovigilância na construção da narrativa telejornalística. Rio de 


\section{REVISTA PAUTA GERAL}

\section{ESTUDOS EM JORNALISMO}

10.5212/RevistaPautaGeral.v.6.i2.00012

Janeiro, 2014. Dissertação (Mestrado em Comunicação) - Departamento de Comunicação, PUC-Rio.

LATOUR, B. Jamais fomos modernos. Rio de Janeiro: Ed. 34, 1994.

LEMOS, A. Cibercultura: alguns pontos para compreender a nossa época. In: LEMOS, A.; CUNHA, P. (Orgs.). Olhares sobre a cibercultura. Sulina: Porto Alegre, 2003.

McCOMBS, M.; REYNOLDS, A. How the news shapes our civic agenda. In: BRYANT, J.; OLIVER, M. B. (Eds.). Media effects: advances in theory and research. New York:

Routledge, 2009.

PARTENOSTRO, V. O texto na TV. Rio de Janeiro: Campus, 1999.

PRIMO, A. Interação mediada por computador. Porto Alegre: Sulina, 2007.

SIBILIA, P. O show do eu. Rio de Janeiro: Nova Fronteira, 2008.

TRAQUINA, N. Teorias do jornalismo: a tribo jornalística - uma comunidade interpretativa transnacional. Florianópolis: Insular, 2008.

TRAQUINA, N. Teorias do jornalismo: porque as notícias são como são. Florianópolis: Insular, 2012.

TUCHMAN, G. La producción de la noticia: estudio sobre la construcción de la realidad. Barcelona: Gustavo Gili, 1983.

VIZEU, A.; CORREIA, J. C. A construção do real no telejornalismo: do lugar de segurança ao lugar de referência. In: VIZEU, A. (Org.). A sociedade do telejornalismo. Petrópolis: Vozes, 2007.

Recebido em: 06/04/2019

Aprovado em: 19/08/2019 